REPRINTED FROM THE

'British Journal of Dermatology'.

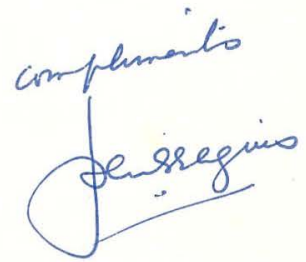

Vol. 76, No. 4, AprIL, Ig64.

PRINTED FOR

H. K. LEWIS \& $\mathrm{Co}_{\text {, LTD., }}$

I36 GOWER STREET, LONDON, W.C.I.

BY

ADLARD \& SON, LTD., BARTHOLOMEW PRESS, DORKING.

\title{
REF
}

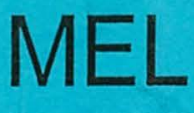




\section{GROUPED PERIORBITAL COMEDONES.}

JOHN R. G. AGIUS, M.D., B.Sc., D.C.H.(Lond.).

The Department of Medicine, Royal University of Malta, Valetta.

CoMrdonms (blackheads), grouped or closely packed in the periorbital area of the face, and not associated with acne vulgaris, have been described by Crocker (1884), Thin (1888), Morris (1911) and many others.

The following investigation was undertaken in order to establish the incidence of grouped periorbital comedones in adults and observe what other conditions were present in persons having these skin lesions.

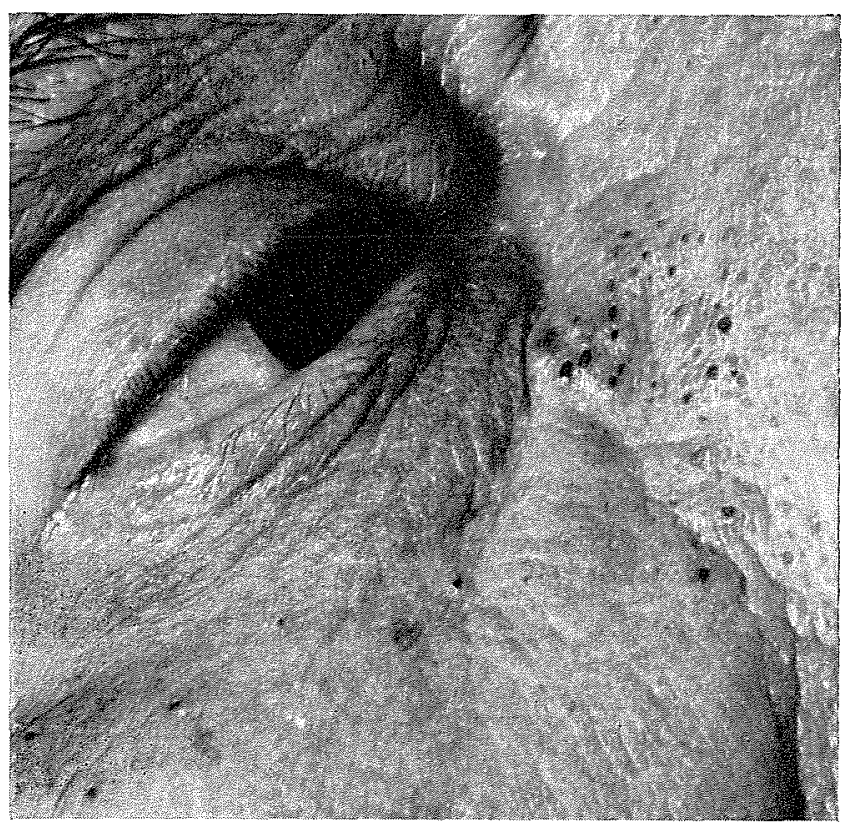

Frg. I.

The observations to be described were carricd out on 2037 patients admitted to a general hospital in Malta. Inclusion in the study was restricted to persons above the age of 35 years, who, on close scrutiny, were seen to have not less than 5 grouped comedones in the periorbital or mask area of the face (Fig. 1).

There were 66 men and 47 women, with an age distribution as shown in Fig. 2.

\section{Results.}

Grouped comedones in the periorbital area were found in $113(5 \cdot 6 \%)$ of the 2037 patients examined. 

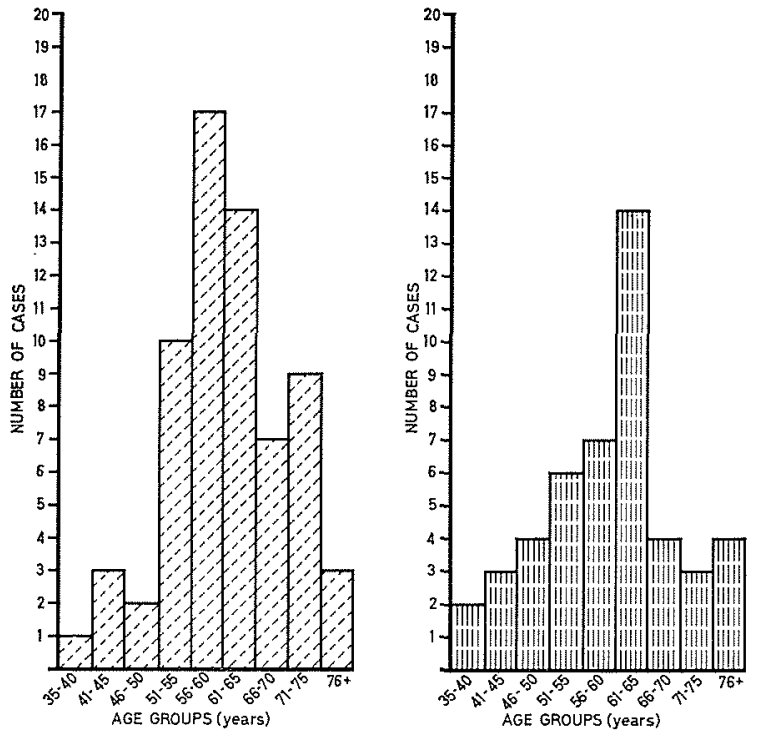

Fra. 2.

Independently of the condition for which they were originally admitted to hospital, the patients were found to fall into one or other of the groups in Table I. Of the 92 cases $(81.4 \%)$ in which the patient was found to suffer

TABLE I.-Associated Diseases.

\begin{tabular}{|c|c|c|c|c|c|}
\hline Group & Disease & & Men & Women & Total \\
\hline 1 & $\begin{array}{l}\text { Diseases of kidney } \\
\text { urinary system and } \\
\text { tension }\end{array}$ & $\begin{array}{l}\text { and/or } \\
\text { hyper- }\end{array}$ & $32(48 \cdot 5 \%)$ & $14(30 \%)$ & $46(40 \cdot 7 \%)$ \\
\hline 2 & $\begin{array}{l}\text { Diseases of kidney } \\
\text { urinary system, hyper } \\
\text { and diabetes mellitus }\end{array}$ & $\begin{array}{l}\text { and/or } \\
\text { tension }\end{array}$ & $8(12 \cdot 1 \%)$ & $24(51 \%)$ & $32(28 \cdot 3 \%)$ \\
\hline 3 & $\begin{array}{l}\text { Diseases of kidney } \\
\text { urinary system }\end{array}$ & and/or & $9(13 \cdot 7 \%)$ & $5(10 \cdot 5 \%)$ & $14(12 \cdot 3 \%)$ \\
\hline 4 & · Hypertension & & $5(7 \cdot 6 \%)$ & $3(6 \cdot 3 \%)$ & $8(7 \cdot 1 \%)$ \\
\hline $\begin{array}{l}5 \\
6\end{array}$ & $\begin{array}{l}\text { Dabetes melltus } \\
\text { (i) Malignant diseases }\end{array}$ & & $8(12 \cdot 1 \%)$ & $1(1 . \pm \%)$ & $\begin{array}{l}2(1 \cdot 8 \%) \\
8(7 \cdot 1 \%)\end{array}$ \\
\hline & (ii) Non-malignant dis & eases & $3(4 \cdot 5 \%)$ & (7) & $3(2.5 \%)$ \\
\hline & & & & $47(100 \%)$ & $113(100 \%)$ \\
\hline
\end{tabular}

from a disease of the kidney or urinary system, $14(12.3 \%)$ had no other complication, $46(40.7 \%)$ had hypertension, and $32(28.3 \%)$ had both hypertension and diabetes mellitus. There were 8 cases ( $7 \%$ ) of uncomplicated hypertension, and $2(1.7 \%)$ of uncomplicated diabetes mellitus. Pyelonephritis was found in $33(30 \%)$ of all the cases and formed $35.8 \%$ of the cases with renal or urinary tract disease. Females with grouped comedones were all found to be suffering from kidney or urinary system disease, hypertension or diabetes mellitus. 
Malignant disease accounted for 17 cases (15\%) and 8 of them had no renal or other disease of the urinary system, hypertension or diabetes mellitus. There were 4 cases of carcinoma of the prostate and two of the three patients with carcinoma of the breast were receiving androgens.

The three non-malignant cases $(2.7 \%$ ) in Group 6 (Table I) were suffering from pulmonary tuberculosis, cirrhosis of the liver and an incompletely investigated macrocytic anaemia respectively. The last two cases, incidentally, had hypotension, of which there was only one other instance.
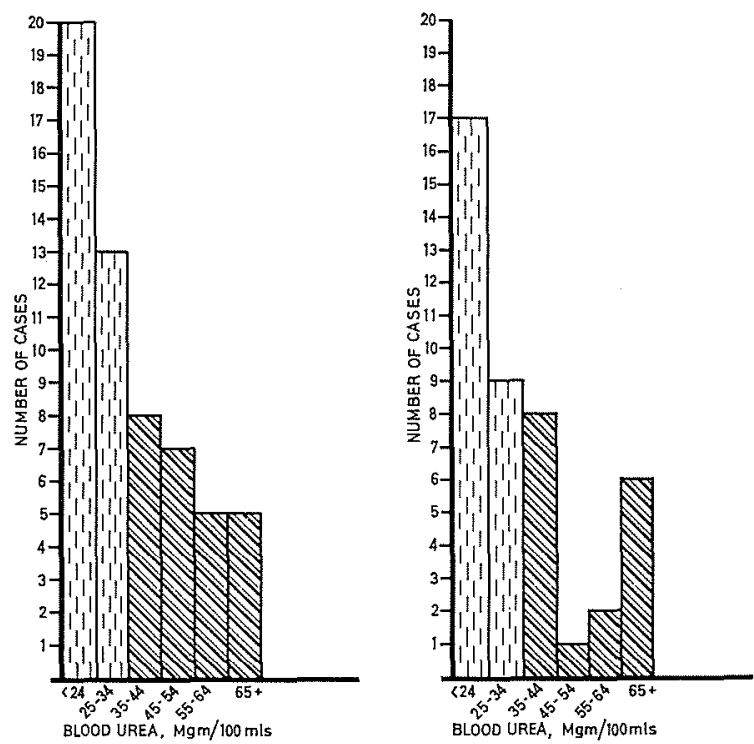

FIG. 3.

Blood urea estimations were carried out in 58 of the male and 43 of the female cases and was found to be raised in $43 \%$ of the male cases and in $39.5 \%$ of the female cases, as shown in Fig. 3.

Amongst the 2037 patients examined there were 10 cases of Parkinsonism, none of them manifesting grouped comedones.

One patient, a man of 67 years, suffering from enlargement of the prostate with retention of urine, had numerous small nodules on many of which there were comedones. These nodules together with many yellow cysts, the size of millet seeds or smaller, were situated chiefly on the forehead, temples and the cheeks. This case has been included in the series even though it seems to belong to the group described by Favre and Racouchot (1951) as "nodular cutaneous elasteidosis with cysts and comedones".

Acne scars were present in only a few of the patients, in most cases the com- 
plexion was smooth and often pasty. There were no cases of trichostasis spinulosa.

TABLE II.-Frequency of Manifestations of Renal or Urinary Tract Disease.

\begin{tabular}{|c|c|c|c|c|c|c|c|}
\hline \multicolumn{3}{|c|}{ Men } & & \multicolumn{4}{|c|}{ Women } \\
\hline & & No. of cases. & & & & & No. of cases. \\
\hline Albuminuria* . & . & $47(70 \%)$ & . & Albuminuria & . & . & $41(87 \%)$ \\
\hline Casts in urine. & . & $24(36 \%)$ & . & Casts in urine & . & . & $16(34 \%)$ \\
\hline Raised blood urea & . & $24(36 \%)$ & . & Raised blood ure & & . & $15(32 \%)$ \\
\hline Pyelonephritis. & . & $23(36 \%)$ & . & Pyelonephritis & . & $\dot{.}$ & $12(25 \cdot 5 \%)$ \\
\hline Prostatic disease & . & $17(25 \cdot 8 \%)$ & . & Uraemia & . & . & $5(10 \cdot 6 \%)$ \\
\hline Cystitis . . & . & $11(16 \cdot 6 \%)$ & . & Nephrolithiasis & . & . & $1(2 \%)$ \\
\hline Retention of urine & . & $7(10 \cdot 6 \%)$ & . & Toxaemia of pr & gnanc & & $1(2 \%)$ \\
\hline Uraemia. & . $\quad$. & $5(7 \cdot 5 \%)$ & . & Uretero-colostom & & $\gamma$ & $1(2 \%)$ \\
\hline Tuberculosis of rena & l tract & $3(4 \cdot 5 \%)$ & . & Cystitis & . & . & $1(2 \%)$ \\
\hline Haomaturia & . $\quad$. & $2(3 \%)$ & . & - & & & - \\
\hline Other causes & . & $3(4 \cdot 5 \%)$ & . & 一 & & & - \\
\hline
\end{tabular}

* Where albuminuria was accompanied by excess of urobilinogen in the urine it was not included in the above figures.

\section{Discussion.}

The comedo is still considered today as the primary lesion in acne vulgaris (Laden, 1959). Most of the work on the mechanism of comedo formation has been made on the comedo of acne vulgaris. For this reason any reference to the mechanism of comedo formation must be related to the hypotheses on the pathogenesis of comedones in acne vulgaris. Cohen (1956) reviewed the various factors influencing this mechanism mentioned in the literature. These may be summarized as follows (after Hellier, 1962).

(i) Hyperkeratosis of the hair follicle due to :

(a) stimulation by androgens

(b) irritation by altered sebum

(c) infection (the staphylococcus being as important as the acne bacillus).

(ii) Abnormal sebum.

Physical and biochemical changes.

(iii) Rudimentary hairs.

(iv) Weak musculi arrectores pilorum.

The hypotheses brought forward on the mechanism of comedo formation in acne vulgaris will be analysed to see whether they can be applied to the comedo formation as found in the present study.

The hyperkeratosis present in acne vulgaris is attributed by Barber (1946) and many others to androgenic influences, the changes being initiated by the biochemical changes in the products of the sebaceous glands (Lever, 1961).

When the present study was planned, a lower age limit of 35 years was instituted in order to exclude, as far as possible the strong androgenic influence 
found in youth. As can be seen in Fig. 1 there were only 6 men and 9 women below the age of 50 years, beyond which the androgenic influence would not be expected to increase but rather to decrease.

Not one of the 10 patients with Parkinsonism encountered in this study had comedones, grouped or otherwise. If the greasiness of the face in Parkinsonism is actually due to seborrhoea (and not to hyperidrosis emulsifying the sebum and making it spread, as is alleged by some), then it is unlikely that a simple increase in sebum production predisposes to comedo formation.

The viscosity of the sebum depends to a certain extent on the amount of evaporation that is taking place, which is common to everybody under similar conditions. The sebum may, however, be secreted in a more viscid state, although this is denied by Kile, Snyder and Haefele (1953).

The arguments which have been brought in support of the contribution to comedo formation by the lanugo hairs and the weak arrectores pilorum muscles are reasonable in themselves. While not denying the possibility or even probability that they do help in the production of the comedo in states other than acne vulgaris, one would have expected, in that case, a much higher incidence of persons with comedones, and the comedones to be more numerous in persons who had these adnexal changes.

The remaining endogenous factor is the alteration of the biochemical properties of the sebum. The present study does not throw any light on this point, but since biochemical changes are known to alter sweat, the possibility of changes in the sebum too deserves further investigation.

Exposure of workers to various oils, tars, petroleum derivatives and dyes, as well as to halogens, metals and metalloids, have resulted in comedo formation either by direct action on the skin or after absorption into the body (Hellier, 1951 ; Wulf and Fegler, 1953).

Heat and moisture as a cause of grouped comedones in infants and children were reported by Crocker 1884, while camphorated oil accidentally transferred from the chest to the face was a notorious cause of comedones early in this century.

The comedo production in the cases in this series cannot be attributed to any of the causes mentioned above. Industry in Malta is practically unknown, and the relatively high incidence of comedones in women (never employed in industry in Malta) further excludes such external causes. The heat to which housewives are exposed in cooking as well as the use of paraffin as the source of the heat, cannot be blamed either, because in that case, one would have expected a younger age group of women to have the comedones, and the incidence to be much higher. Again, this argument would exclude most of the men.

The association of grouped comedones with various internal diseases has been recorded several times in the past. Morris (1911) felt that grouped 
comedones seemed to be aetiologically related to dyspepsia. Riecke (1925) mentioned their presence in anaemias and "grave" diseases, while Ormsby and Montgomery (1954) recorded their observation also in cachectic patients. The presence of filiform comedones in riboflavin deficiency (Sydenstricker, 1941) and in pellagra (Smith, 1943) are more specific associations. The presence of grouped comedones in cirrhosis of the liver, carcinomata and certain diabetic patients in this series may well belong to the groups described by Sydenstricker and Smith (see also Goldsmith and Hellier, 1954).

An interesting parallel can be seen in the identical histological appearance of lichen spinulosus and the comedo of acne; the former appearing occasionally in association with the acute stage of kerion ringworm. (Percival, Montgomery and Dodds, 1962).

The rest of the cascs forming the bulk of tho group howovor, showed a strong association with renal disease or diseases of the urinary system, an association which, as far as can be ascertained, has not so far been reported. This relationship is difficult to explain, though a dermo-renal association is seen in the appearance of "frost" on the skin terminally in uraemia (Allen, 1952). The similarity of effect produced by corticosteroids on sweat glands and renal tubules (Guyton, 1961) seems to support this association. It is suggested here that metabolic or endocrine changes in the body, having altered the sebum biochemically, provoke comedo formation.

The presence of grouped comedones principally in the periorbital area is presumably due to this being the region where secretion of sebum is most abundant and rudimentary hairs quite common. In certain areas, such as the forehead and cheeks, a true seborrhoea may persist into old age (Wells, 1954).

\section{SUMMARY.}

One hundred and thirteen cases of grouped periorbital comedones have been studied.

A high incidence of renal or other urinary disease, often associated with hypertension and diabetes mellitus, was observed.

The method of comedo production is discussed.

I wish to thank the consultants of St. Luke's Hospital, Malta, for facilities given to me.

\section{References}

Allen, A. C. (1952) The Kidney. London : J. and A. Churchill.

Barber, H. W. (1946) Practitioner, 156, 333.

CoHen, E. L. (1956) Brit. J. Derm., 68, 362.

Crocker, H. R. (1884) Lancet, i, 740.

Favre, M. and Racovchot, J. (1951) Ann. Derm. Syph., Paris, 78, 681.

GoldSMITH, W. N. and HeLLIER, F. F. (1954) Recent Advances in Dermatology, 2nd ed. London H. K. Lewis.

Gurton, A. C. (1961) Medical Physiology 2nd ed. Philadelphia : Saunders.

VoL. 76. 
Helligr, F. F. (1951) in The British Encyclopaedia of Medical Practice, 2nd ed. London: Butterworth.

- (1962) Practitiones, 188, 589.

LADEN, E. L. (1959) in Modern Dermatologic Therapy, ed. T. H. Sternberg and V. D. Newcomer. London : McGraw-Hill.

Lever, W. F. (1961) Histopathology of the Skin, 3rd ed. London : Pitman.

MoRris, M. (1911) Diseases of the Skin, 5th ed. London : Cassell.

Prrcival, G. H., Montgomery, G. L. and DodDs, T. C. (1962) Atlas of Histopathology of the Skin, 2nd ed. Edinburgh and London : Livingstone.

Rrecke, E. (1925) Manuale delle Malattie della Pelle 2nd Italian ed., (7th German ed.). Milan : Societa Editrice Libreria.

Smrth, D. T. (1943) Med. Clin. N. Amer., 27, 379.

ThIN, G. (1888) Lancet, ii, 712.

WeLLS, G. C. (1954) J. Amer. geriat. Soc., 2, 535.

WULF, K. and FEGELER, F. (1953) Hautarzt, $4: 371$. 